\title{
Refrigerator Efficiency in Ghana: Tailoring an appliance market tranformation program design for Africa
}

\author{
Essel Ben Hagan, \\ CSIR Institute for Industrial Research, P.O. Box LG 576, Legon, Accra, Ghana \\ Robert Van Buskirk, \\ Lawrence Berkeley National Laboratory,One Cyclotron Road, MS: 90R4000, Berkeley, CA, \\ 94720 \\ Alfred Ofosu-Ahenkorah, \\ Ghana Energy Foundation, 5 East Legon, P.O. Box CT1671, Cantonments, Accra, Ghana \\ and \\ Michael A. McNeil, \\ Lawrence Berkeley National Laboratory,One Cyclotron Road, MS: 90R4000, Berkeley, CA, \\ 94720
}

\begin{abstract}
In some cases, a simple replication of developed country appliance efficiency labels and standards may not be completely feasible in Ghana and many other countries in Africa. Yet by creatively modifying the developed country appliance efficiency market transformation model, it should be possible to achieve dramatic energy use reductions. As was true in developed countries in the previous two decades, refrigeration efficiency improvements provide the greatest energy savings potential in the residential electricity sector in Ghana. Although Ghana, like many African countries may impose standards on imports since Ghana does not have manufacturing facilities for appliances in country. This approach may hurt some consumers who patronize a very diverse market of used appliances imported from Europe. We discuss how meeting the challenges of the Ghanaian market will require modification of the usual energy efficiency labeling and standards paradigm. But once a refrigerator market transformation is accomplished in Ghana, we estimate an average energy savings potential of 550 $\mathrm{kWh} /$ refrigerator/year, and a monetary savings of more than $\$ 35 /$ refrigerator/year. We discuss how this modified refrigerator efficiency market transformation may occur in the Ghanaian context. If successful, this market transformation is likely to be an example for many other African countries.
\end{abstract}

Keywords: energy efficiency, market transformation, Africa energy policy 


\section{Table of Contents}

- Introduction and Motivation

o The Needs and Context of Energy Development in Africa

o The Benefits of Appliance Efficiency

o Refrigerator Energy Use in Africa

- Some Challenges of Appliance Efficiency Market Transformation in Africa

o Diversity of Countries and Context

o The Scarcity of Investment Capital

o Enforcement and Informal Markets

- Strategies for Meeting African Appliance Efficiency Program Challenges

o Create a Diverse Network of National Efficiency 'Champions'

o Measurement and Monitoring of Refrigerator Efficiency

o Refrigerator Design, Rehabilitation and Engineering

o Curriculum and Educational Program Development

o Market Transformation 'Pilot Projects'

o Decreasing Development Aid Overheads

- The Potential Benefits of Refrigerator Efficiency Improvement in Ghana

o Refrigerator Energy Use in Ghana

o The PAMS Efficiency Policy Impact Model

o Model Inputs and Assumptions

o Model Results

- Net Present Value of Economic Benefits

- Carbon Emissions Reductions

o Program Funding Levels

- Conclusions and Recommendations

- REFERENCES 


\section{Introduction and Motivation}

In developed countries, market transformation initiatives to improve the efficiency of residential appliances have been highly beneficial (Meyers et.al, 2002, 2003). In this paper, we examine the possibility of replicating the success of appliance efficiency market transformation in less developed countries by designing an "Initiative for Improved Refrigeration Efficiency in Ghana, Africa." Such an initiative would attempt to facilitate market transformation activities that would replace high energy use refrigerators with efficient residential refrigerators and refrigeration services.

While there have been some notable initiatives to improve the efficiency of refrigeration services in developing countries, the problem of inefficient refrigerators in Sub-Saharan Africa remains largely unsolved. To date, there are no mandatory energy efficiency standards for refrigerators in Africa (CLASP, 2005). The lack of standards exists in spite of the possibility that refrigerator efficiency may be one of the most cost-effective and environmentally beneficial methods for expanding electricity-based energy services supply on the continent.

Of the countries in Africa, Ghana is one of the most advanced in terms of promulgating energy efficiency regulations for electrical appliances. Ghana is the only country in sub-Saharan Africa with mandatory efficiency performance standards as of the year 2005, and one of only three countries on the continent with labeling and testing standards (CLASP, 2005).

But in spite of the substantial work by previous studies there has not been to date an accurate and detailed estimate of refrigerator energy use in Ghana. A 1999 
study regarding the potential of energy efficiency standards in Ghana (Constantine et.al., 1999) estimated annual refrigerator energy use with European data (for the sake of energy efficiency policy analysis) as $591 \mathrm{kWh} /$ year with a potential energy use of $409 \mathrm{kWh} /$ year for more efficient models. An energy efficiency standards impact analysis for Pakistan (Shrestha et.al., 1998) in contrast to the Europeanbased estimate, forecasted annual use amounts of $1314 \mathrm{kWh} /$ year for the base case and 788 for the efficiency case. In this study we estimate an average annual energy use of $1140 \mathrm{kWh} /$ year for a sample of approximately 100 refrigerators in residences in Ghana's capital, Accra. This energy use is more than twice what is allowed by mandatory energy performance standards (MEPS) in the U.S. and Europe.

The first step of designing a market transformation program is to understand the socio-economic needs and context for energy efficiency activities in Africa. Adapting policies and programs to the existing context will be an essential element of market transformation methods that are appropriate to Ghana.

\section{The Needs and Context of Energy Development in Africa}

With per-capita gross national product in Sub-Saharan Africa in the range of \$100 to $\$ 2000 /$ capita (for $80 \%$ of African countries) and average life expectancy at 46 years (UNDP, 2005), it is not surprising that there are many basic and urgent needs are not being met for large portions of the population. According the 2005 Human Development Report in Sub-Saharan Africa (UNDP, 2005), HIV prevalence is $7.3 \%$, under five mortality rates are $179 / 1000,30 \%$ of children are undernourished, and $42 \%$ of the population does not have sustainable access to improved water sources (and the improved water sources that are available are not 
necessarily safe or clean). Even though in this context, access to electricity and refrigeration may seem like a luxury, the economics of electricity and modern energy access and supply plays a key role in economic development and efforts to increase living standards.

Taking an average of a cross-section of 17 Southern and Eastern African countries (Karakezi et.al., 2004) one obtains an average national electrification of about $25 \%$ and an average urban electricity access rate of $45 \%$ in $2000-2001$. The price of electricity varies between $\$ 0.02$ to $\$ 0.12 / \mathrm{kWh}$ for these countries averaging \$0.068/kWh (1998-2001).

The socioeconomic conditions for Ghana are above average for sub-Saharan Africa, with five countries in ranking higher than Ghana on the UN's human development index, and 32 sub-Saharan countries ranking lower. The year 2000 national census (Ghana Statistical Service, 2005) estimated Ghana’s total population as 18.9 million, living in 3.7 million households. The year 2000 census found $44 \%$ of households using primarily electric — rather than kerosene-lighting. Meanwhile, the International Energy Agency estimates total residential electricity consumption at 1650 GWh in 2002 (IEA, 2005). This leads to an estimate of average household electricity consumption of slightly less than 1000 kWh/year/household for those households using predominantly electric lighting (accounting for population growth from 2000 to 2002). This is more than ten times lower than the average U.S. household electricity consumption of 10,656 kWh/year/household in 2001 (EIA, 2005a). 
Recent data from Ghana indicates that the average marginal price of electricity (as is described in more detail below) is $\$ 0.065 / \mathrm{kWh}$, compared to a value of \$0.099/kWh for the U.S. (EIA, 2005b)

\section{The Benefits of Appliance Efficiency}

In developed countries, the enhancement of appliance energy efficiency has been highly beneficial and has been implemented primarily through testing standards, labeling, and mandatory efficiency performance standards (MEPS). In the U.S., the process of standards development reversed the long term trend of increasing refrigerator energy use in the 1960's and 1970's and has resulted in a factor of three improvement in refrigerator efficiency. Current efficiency regulations are expected to save a net total of $\$ 80$ billion (present value of savings in year 2001 dollars) for the U.S. economy by 2015, with an average benefit cost ratio of 2.75:1 for a long term period of analysis from 1987 - 2050. (Meyers, et.al. 2003).

\section{Refrigerator Energy Use in Africa}

Some lesser-known refrigerator efficiency and energy use studies indicate that the refrigerator energy use per appliance (and the potential savings per appliance) may be substantially greater in Africa than for refrigerators in developed countries (Cornut, 2005). This may occur due to a variety of factors including: (1) higher ambient temperatures and humidity, (2) the prevalence of old, used and poorly reconditioned refrigerators, (3) more intensive use of refrigerators for productive and commercial activities, and (4) voltage and power supply fluctuations and inefficient use patterns that respond to such fluctuations. This combination of factors can conspire to create energy use rates greater than $5 \mathrm{kWh}$ /day for 
refrigerators in Africa. Meanwhile for comparison, the current estimated refrigerator energy use in the U.S. is approximately $1.9 \mathrm{kWh} /$ day (Meyers et.al. 2003).

In the rest of this paper we discuss the possibilities and the potential methods for expanding appliance efficiency market transformation activities to systematically include refrigerators in Ghana in particular with potential applications to Africa in general. We begin with a description of some of the challenges of doing appliance efficiency market transformation in Africa. We then describe a series of programmatic strategies for potentially meeting these challenges. We proceed to an analysis of the potential benefits of refrigerator efficiency market transformation in Ghana. Then, given the economic, social, and environmental benefits of refrigerator efficiency improvements and the corresponding programmatic challenges, we provide an estimate of a minimum programmatic international aid support budget for these activities. We end the paper with conclusions and recommendations regarding Ghanaian and African refrigerator efficiency market transformation.

\section{The Challenges of Appliance Efficiency Market Transformation in}

\section{Africa}

Africa is an incredibly diverse continent that is socially, politically, and economically complex. Even at a national scale, most countries in Africa have extreme levels of ethnic, social, and economic diversity amongst the regions and the thousands of rural villages and communities. In addition, the scarcity of income, buying power, capital, finance, and resources makes Africa a very challenging environment in which to organize policies and programs. In spite of 
such challenges, it is possible to make progress. To make such progress, the challenges of the African policy and programmatic environment need to be addressed so that programs can be designed in ways that are compatible with this complex organizational environment.

The approach for appliance energy efficiency market transformation promoted by the Collaborative Labeling and Appliance Standards Program (CLASP) is one where "mandatory energy-efficiency standards transform markets by removing inefficient products," and "Energy labels empower consumers to make informed choices about the products they buy and to manage their energy bills.” (Weil and McMahon, 2005, p.3) This approach is quite appropriate for a socioeconomic environment where specialized government institutions can predictably modify commercial activity through regulation. But in much more informal economic and regulatory environments where appliance distribution and repair markets are only partially connected to a regulated commercial environment, a more savvy market transformation approach may need to be taken to confront the particular challenges of this market.

The CLASP approach to efficiency market transformation assumes that government policy makers and their institutions will be the agents of change: "The authors have written this guidebook to assist policy makers and the institutions they represent in introducing energy-efficiency labeling and standardssetting programs.” (Weil and McMahon, 2005, p.4) Ghana has used this approach in close collaboration with stakeholders to develop and adopt its first energy efficiency standard for room air conditioners. In the case of refrigerators, it is very likely that the energy-efficiency transformation will once again be driven by 
stakeholders and policy-makers. But substantial resources may need to be invested in both public education and technical support to appliance suppliers, distributors and repair shops to help implement a MEPS. Ghana and many of the African countries do not have manufacturing facilities for appliances and therefore have mainly suppliers and traders as stakeholders. Neverthesless in this process the methods of market transformation may need to be re-examined given the substantial institutional and market capacity-building needs that exist.

In re-examining the potential market transformation process in Ghana, we discuss three challenges of African appliance markets including: (1) the diversity of conditions at country-level, sub-national, and community scales, (2) the shortage of capital and investment resources, and (3) the challenges presented by weak enforcement infrastructure and informal markets.

\section{Diversity of Countries and Context}

In Africa's 54 countries, hundreds of regions, and hundreds of thousands of communities, there is a large diversity of conditions that can impact the implementation of an efficient refrigerator market transformation program. These can include:

1. Distribution and supply chain for refrigerators that varies by refrigerator type (new, used, or rehabilitated), country of origin, and production mode (locally produced, locally rehabilitated, imported, and/or assembled)

2. Climatic conditions which affect refrigerator energy use

3. Cost of electricity

4. Level of subsidy for electricity supply 
5. Fuel source and types of electricity generation

6. Level of electrification

7. State of markets in the country, including the interaction between formal and informal markets

8. The fuel type, equipment age, and efficiency of electricity generation

9. Types of electricity supply organizations (i.e. private, public, state-run)

10. Import/export regulations

11. Government organization and capacity for regulatory enforcement

12. Feasible rate of energy policy formulation and change within relevant government institutions

13. Exchange rate stability, foreign currency availability and inflation

14. Strength of the banking system

15. Cost and availability of capital

16. Level of awareness among the population of energy efficiency and the implications of more efficient appliances con expenditure of energy.

In the particular case of Ghana, the environment for advancing energy efficiency regulations is characterized by the following:

1) More than half of refrigerators sold in Ghana are used, with poorer households being very likely to purchase a used refrigerator. There is an organized network of refrigerator and air conditioner sale and repair shops with at least 5000 members. Used refrigerators are shipped directly to Ghana from Europe for resale of on the local refrigerator market.

2) Climatic conditions are hot and humid with average ambient temperature between 28 and 30 degrees Celsius. 
3) Cost of electricity

a) The marginal price of electricity for the residential sector is zero for consumption less than $50 \mathrm{kWh} /$ month, $\$ 0.064 / \mathrm{kWh}$ for consumption in the range of 51-300 kWh/month, and $\$ 0.112 / \mathrm{kWh}$ for consumption greater than $300 \mathrm{kWh} /$. month.

b) The marginal price of electricity for the commercial sector is $\$ 0.093 / \mathrm{kWh}$ for consumption in the range of $0-300 \mathrm{kWh} /$ month, and $\$ 0.114 / \mathrm{kWh}$ for consumption greater than $300 \mathrm{kWh} /$. month.

4) In the commercial sector, at the margin, electricity is not subsidized on average.

5) Access to electricity is $44 \%$ in the year 2000 (Ghana Statistical Service, 2005)

6) Informal markets are dominant ( $80 \%$ of workers are employed in the private, informal market (Ghana Statistical Service, 2005)), but government regulation and education have a large impact on informal markets.

7) Electricity supply is majority hydropower, but new generation is from light oil fired thermal plants

8) There is one state-owned electricity generation company that also purchases electricity from private generators through power purchase agreements. And a state-owned distribution company that is responsible for power distribution in the southern part of the country.

9) Import/export regulations function well, though if regulations are unpopular, people will find a way around them

10) The government capacity for regulatory enforcement is good, especially if there is an accompanying public education campaign 
11) The feasible rate of energy policy formulation and change within relevant government institutions is likely 2-5 years for an energy efficiency regulation

12) Foreign currency can be freely exchanged at market rates and inflation ranged from 15 - 33\% for 2000 through 2003 and 14.72\% in October 2005. (Ghana Statistical Service, 2005)

13) The prime rate in Ghana in November 2005 was $15.5 \%$ and averaged $20 \%$ in 2002-2004

At least two of these issues or conditions are particularly problematic for countries in Africa: cost and availability of capital/investment, and the issues of enforcement and informal markets.

We discuss these two issues in more detail below.

\section{The Scarcity of Investment Capital}

Shortages of capital for investment in Africa can be extreme, especially when this capital is required in cash form, and needs to be available in foreign currency. With inflation at $15 \%$ to $33 \%$ and interest rates at a minimum in the range of $15 \%$ to $20 \%$, the high cost of capital results in a demand for short payback times for household level investments which can lead to a lack of willingness to make energy efficiency investments. Thus while it may be fairly straightforward to assume that households in developed countries have the means of financing the higher cost of a more efficient appliance, this often will not be true in a developing country context, especially when the cost of the appliance may exceed one to several month's household cash income. 


\section{Enforcement and Informal Markets}

Another key challenge to improving the efficiency of appliances in Africa is the lack of a ready institutional infrastructure that is necessary for implementing the strategies that have been successful in more developed countries. In a typical appliance efficiency improvement program, initially a test procedure for energy use is developed. Then a labeling program based on the test procedure provides information to the market on energy use and efficiency, and often mandatory efficiency performance standards are imposed upon the manufacturers and importers of appliances. (Weil and McMahon, 2005) Energy performance standards in the U.S. and other countries often explicitly exclude used appliances, though they do apply to any used appliances that might be imported. The rationale for the exclusion of the used market is that it is too difficult to enforce regulations, and eventually the more efficient appliances propagate into the used appliance market.

In many parts of Africa, imported, used appliances are often the primary source of appliance supplies, and the technical capacity of customs officials to enforce energy efficiency regulations on imported appliances may be quite limited. Also the informal sector may rehabilitate, rebuild and reuse appliances for many years after initial manufacture. This presents a distinct challenge for rapid efficiency improvements because it may take many years to build the enforcement capacity to test and monitor new and imported appliance efficiency. And it may take decades for higher efficiency products to propagate into and through largely informal used and rebuilt appliance markets. 


\section{Strategies for Meeting African Appliance Efficiency Program}

\section{Challenges}

In this section we present some of the planned activities and strategies for meeting some of the challenges of refrigerator efficiency improvement in Ghana and Africa in general. Key elements of this strategy will be enabling and supporting a large diversity of approaches that can respond to the multiplicity of conditions represented by different countries, regions and communities. We focus on concrete, measurable results, and providing consistent, long term sustenance of national or local appliance efficiency 'champions' that can push the cause of efficient appliance market transformation according to the political, social, and economic conditions of their particular countries and locales.

\section{Create a Diverse Network of National Efficiency 'Champions'}

Responding appropriately and effectively to the local and national conditions, politics, economics and social conditions requires a deep knowledge of the local situation. This knowledge cannot be obtained overnight and must reside in someone with many years of organizational experience in-country. The network of people that need to partner in implementing an efficient appliance market transformation must have both a personal and organizational long-term commitment to furthering energy efficiency. Thus our strategy for confronting the diversity of conditions and challenges facing refrigerator markets will be to network and partner with such local efficiency champions. Many countries already have one to several very active people who have made a career and lifelong commitment to enhancing energy efficiency in their country, so the initial ingredients for such energy efficiency policy networks already exist. This is 
especially true in Ghana where energy efficiency policies and programs have been under development and implementation for more than a decade. In other countries there are many influential actors who may be converted to national energy efficiency champions once they are apprised of the economic and social benefits possible from efficiency improvements. This network can be strengthened further by developing lasting, sustained relationships and partnerships with energy efficiency implementers abroad.

In building such a network it is very important not to build effervescent partnerships, but to have reliable, long-term technical and financial support for those national efficiency improvement efforts that show strong signs of success. Thus any such national or regional-scale appliance efficiency initiatives must have a solid commitment and support (more than 5 years), and substantial results-based funding. If energy efficiency policy support networks cannot respond to the success of national champions with increased support, services and commitment, then this sends the message to national partners that concrete success is not important or valued. Such a signal can de-motivate results-based progress.

For the Ghana refrigerator market transformation effort, this network is comprised of a range of stakeholder, academic, governmental and non-governmental organizations including: the National Air-Conditioning and Refrigeration Workshops Owners Association (NARWOE), CSIR-Institute of Industrial Research, the Energy Foundation, the Energy Commission, Kwame Nkrumah University of Science and Technology (Department of Mechanical Engineering), all in Ghana, and the Energy Efficiency Standards Group of Lawrence Berkeley National Laboratory, California, USA. 


\section{Measurement and Evaluation of Refrigerator Efficiency and Program}

\section{Impacts}

CSIR-Institute of Industrial Research and the Energy Foundation began a program of surveying in-situ refrigerator energy use in Ghanaian households in 2005. The Energy Foundation with funding and support from the Votage River Authority and CLASP conducted a household energy profile study in 2003-2004. This early energy use data collection helps define the dimensions of the refrigerator inefficiency problem in Ghana and the savings potential from energy efficiency improvements.

Continuing monitoring, evaluation and verification of program results will be a key component to maintaining and growing both national and international support for refrigerator efficiency market transformation programs in Ghana and other African countries. This is especially true since as we show below, there may be relatively substantial carbon emissions reduction benefits which can provide a valuable contribution to greenhouse gas emissions reductions. In addition such monitoring and evaluation will be a key element to the international learning process that will help propagate the most successful market transformation experiences to the greatest number of relevant contexts.

Even with the initial data collection efforts, there is only the sparse information regarding actual refrigerator energy use in Ghana. Thus a first, high priority step of a larger refrigerator efficiency effort is establishing a consistent program of measuring refrigerator efficiency and energy use. Such a measurement program can utilize a combination of methods including (1) Laboratory measurements according to adaptations of standard refrigeration efficiency measurement 
protocols, (2) Survey type measurements of actual energy use in individual households, and (3) Quick evaluation energy use measurements of refrigerators in stock in stores and refrigerator distributorships.

\section{Refrigerator Design, Rehabilitation, and Engineering}

Because of the very large used and rehabilitated refrigerator market, methods for increasing the efficiency of refrigerators in local workshops need to be examined. Some of these might include changing out compressors and condensers to more efficient models, increasing insulation, and adjusting the charge of the coolant. To the extent that the added cost of efficiency can be invested in a local industry of refrigerator efficiency rehabilitation, an initiative to promote and increase refrigerator efficiency in the used and rehabilitated fridge market can contribute to the stimulation of the national economy and create added revenues and employment for refrigerator rehabilitators and distributors.

The specific activities that may be included in the refrigerator design work may include refrigerator efficiency rehabilitation design contests, university research in refrigerator rehabilitation and design, capacity building and training in refrigerator efficiency evaluation and design for repairers and shop owners, and publication and distribution of a refrigerator efficiency rehabilitation/repair manual.

\section{Public Education, Curriculum and Educational Program Development}

Another key element of a refrigerator efficiency market transformation program will be enhancing education and awareness regarding refrigerator energy use and efficiency amongst the public, and collecting data and information at the grassroots level. We believe that a key element of this work will be developing 
curriculum regarding energy efficiency and energy use at the high school level, as part of teaching high school science in a way that motivates both students and teachers. Initial efforts have been made to demonstrate the use of simple electricity meters as an educational tool that can be used for educational home energy audits that can teach students the connection between science, physics, energy and concrete economic savings in the household.

In addition to high school curriculum development and student measurement and research activities, another key element of efficiency program education will be general public education. This can be done through the use of the mass media to sensitize both consumers and retailers of refrigerators about energy use and efficiency. Public education documentaries and programs will be another essential component of a market transformation campaign.

\section{Market Transformation 'Pilot Projects'}

Another key component to developing a successful strategy for refrigerator efficiency market transformation in Ghana and elsewhere in Africa may be to implement, when possible, a diversity of market transformation pilot projects. Such pilot projects may involve experimental, small-scale testing and labeling programs, community-scale market transformations, specific refrigerator repair and rehabilitation programs, etc. While there is substantial experience to date with respect to labeling and standards in developing countries, new applications and changing economic and political conditions necessitate continued experimentation with market transformation strategies. Ghana has already developed an efficiency label for appliances and as this label is adapted and applied to the refrigerator 
efficiency programme, testing and evaluation of the lable impacts should be performed.

\section{Decreasing Development Aid Overheads and Transaction Costs}

One of the key barriers to the implementation of energy efficiency programs and research in African countries is actually the transaction cost of international funding for such programs. Given the very low research labor costs in many African countries, the actual cost of monitoring, data collection, training and program development are very low by developed country standards. But given the typical 100:1 ratio of research labor costs between African and developed countries, and the developed country orientation of the funding paperwork requirements, it is often very difficult to formulate country-level proposals without a very substantial investment in foreign consultancy services even at the very early stages of program formulation.

Because replacing highly inefficient refrigerators with more efficient ones may have very high benefits relative to costs, maximizing the benefits of a regional market transformation program will require making sure that a maximum of funds is spent on programs that result in actual refrigerator efficiency enhancements rather than studies or consultancies regarding what might be needed or desired. We assert that the benefits of refrigerator efficiency improvement in Ghana and Africa are clear, and that what is needed at this time are practical programs and implementation strategies that can be shown to be effective in the complex African socio-economic context. Thus any resources devoted to discussing regional or national initiatives, must be matched with much greater amounts of funding for actual implementation. 
For the effort described in this paper to be possible, at least $\$ 35,000$ worth of international technical support (expenses +1 full time equivalent month of labor) effort has been expended on a largely volunteer basis. This is equivalent to the budget of six months to one year of full time data collection, monitoring, educational and testing work on the part of the Ghanaian partners.

\section{The Potential Benefits of Refrigerator Efficiency Improvement in}

\section{Ghana}

In this section we use preliminary energy use monitoring data from refrigerators in Ghana to estimate the potential impacts of refrigerator efficiency market transformation programs. 


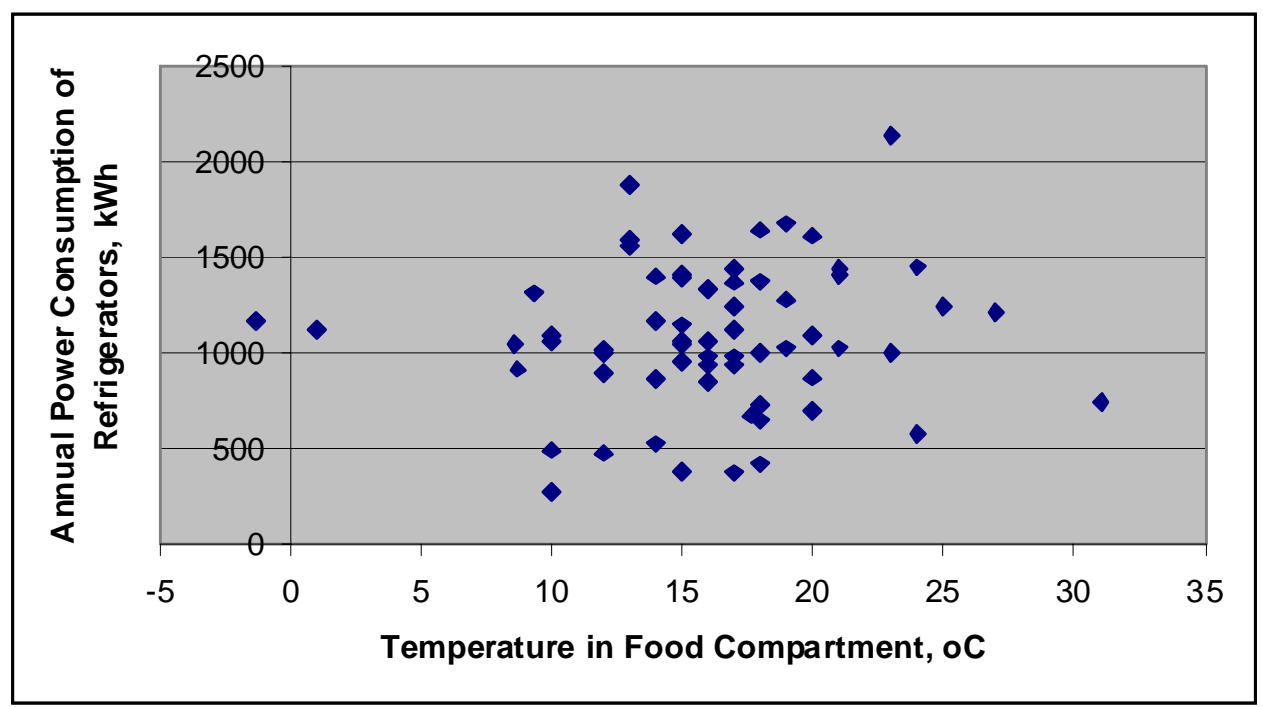

Figure 1: Power Consumption of Refrigerators vs. Temp. in Food

\section{Compartment}

\section{Refrigerator Energy Use in Ghana}

The data on refrigerator energy use in Ghana was recently gathered through household monitoring survey conducted by the CSIR-Institute of Industrial Research. In this data collection exercise, research staff visited a sample of households in Accra, Ghana and conducted both a short household survey and monitored the energy use of any refrigerators for 24 hours (for a minimum of 15 hours and a maximum of 24 hours). The data was collected with an SEM cumulative electricity use meter. The data is presented in figures 1 and 2.

Figure 1 shows the energy use as a function of the food compartment temperature. Note that for this data the ambient temperature is relatively constant at 29 degrees Celsius. The interesting feature of this data is that if anything, there is a weak positive correlation between the internal temperature of the refrigerator and the energy use. Normally one would expect energy use to increase with lower 
internal temperature since it takes more energy to pump a given amount of heat across a larger temperature difference. But in this case, we have cross-sectional data, and the internal temperature is likely to be indicative of refrigerator insulation or door seal problems. Given a limited heat pumping capacity, a high internal temperature occurs for the inefficient refrigerators that uses more energy and cannot keep the interior of the refrigerator ideally cool, because heat leaks in as fast as it can be pumped out.

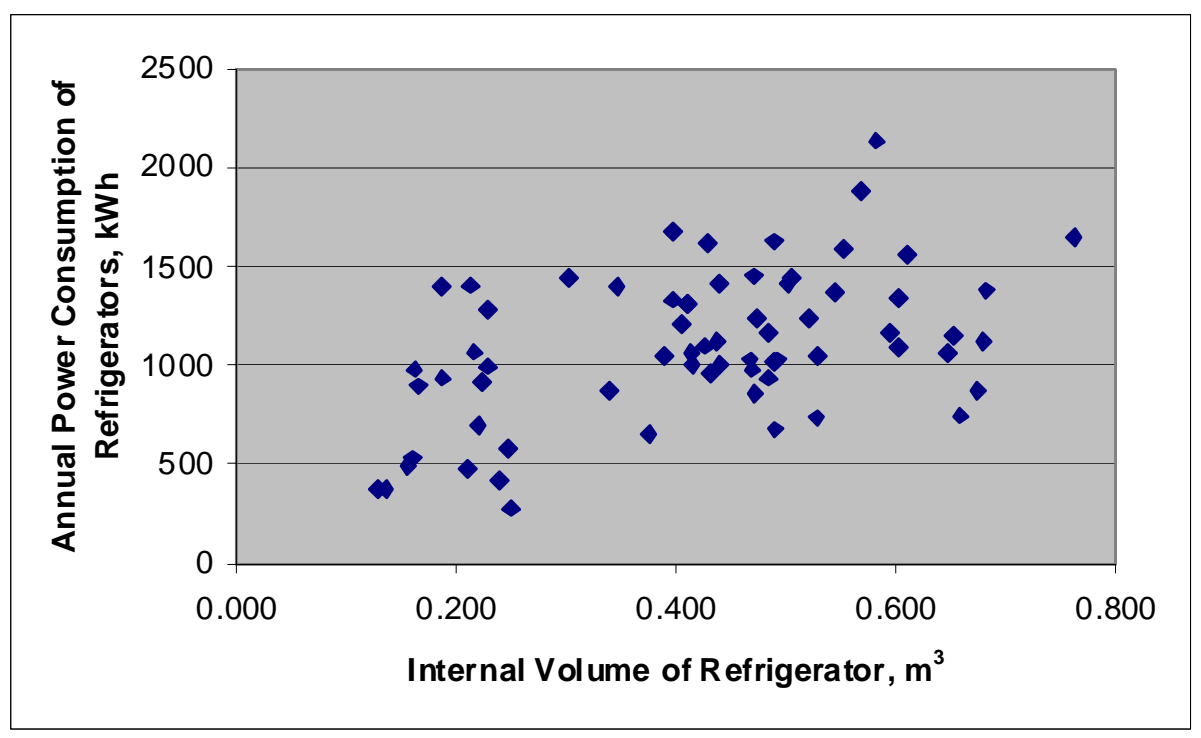

Figure 2: Power Consumption of Refrigerators vs Internal Volume

Figure 2 shows the energy use as a function of the internal volume of the measured refrigerators. Again, the common or expected relationship between refrigerator volume and energy use is not seen. Given the complete lack of information regarding refrigerator energy use and efficiency in Ghana, there is very little correlation between energy use and refrigerator volume or size. The variation in energy use due to inefficiency is much greater than the variation due to refrigerator volume or size effects. 


\section{The PAMS Efficiency Policy Impact Model}

The Collaborative Labeling and Appliance Standards Program (CLASP) was founded in order "to facilitate the design, implementation, and enforcement of energy efficiency standards and labels for appliances, equipment, and lighting products in developing and transitional countries throughout the world." As part of its mission, CLASP has developed the Policy Analysis Modeling Spreadsheet (PAMS) in order to provide an easy-to-use software tool to help local policymakers assess the benefit of standards and labeling programs, and to identify the most attractive targets for appliances and efficiency levels. PAMS is available via the CLASP website at http://www.clasponline.org.

The objective for PAMS in calculating policy cost/benefits is to provide a fairly comprehensive accounting of the costs and benefits for several different appliances in a single spreadsheet. Further, the tool is constructed in such a way that a wide variety of country scenarios can be accommodated through user selection of macro-level forecast data. The over-all cost benefit accounting model can be described in terms of several component models that provide important inputs for the final aggregate cost/benefit calculation.

The efficiency policy analysis model calculates the costs and benefits of efficiency standards from two distinct but related perspectives:

- The Consumer Perspective: examines costs and benefits from the perspective of the individual household or enterprise. The calculation from the consumer perspective is called the Life-Cycle Cost (LCC) calculation. 
- The National Perspective: projects the total national costs and benefits including both financial benefits, and energy savings and environmental benefits. The national perspective calculations are called the National Energy Savings (NES) and the Net Present Value (NPV) calculations.

\section{Model Inputs and Assumptions}

In order to provide a first-order estimate of the impact of standards in a wide variety of countries, PAMS relies on proxy engineering data from countries where technologies are well understood and where economic and population data are publicly available. A more accurate estimate of policy impacts can be produced by the spreadsheet in cases where local experts have detailed local data on hand.

- Engineering Data - In the event that detailed engineering calculations have been made for typical products in the country, these can be entered in terms of the fractional efficiency improvement and corresponding equipment cost increase, for up to six design technologies.

- $\underline{\text { Shipments }}$ - Although appliance sales forecasts are difficult to obtain at a global level, often these can be estimated by local experts. Common sources of shipments forecasts are manufacturer industry associations or, in the case of import-dominated markets, by data provided by customs or other government agencies. A full shipments forecast can be entered, thus bypassing the econometric ownership-driven model.

- Appliance Data - Even if no detailed engineering data is available for the country being modeled, prevalent prices in the market can be taken into account. In this case, the engineering and cost factors are scaled by the prevalent baseline retail equipment price. 
- $\quad$ Energy Sector Data - Accuracy of estimates can be greatly improved if certain parameters concerning the generation and sale of energy are known. These include: Current prices for electricity paid by residential consumers (according to prevailing tariff structures); Site to Source Conversion Factor (according to fuel mix); Transmission and Distribution Losses and; Carbon Emissions Factors. In the current version of the spreadsheet, default assumptions are made about generation mix. These are highly variable from country to country, however. Therefore, this is an area for which user inputs can greatly increase the accuracy of assessments.

- Economic Data - The econometric model forecasts future economic growth according to the trends over the period 1975-2000 in order to minimize fluctuations over recent years. This may be significantly different than the most accurate forecasts (provided by national financial ministries or international sources).

In our application of the PAMS model we used the average energy consumption measured in our Accra sample of 100 homes of $1140 \mathrm{kWh} /$ year as the baseline energy use, and assumed that standards programs could reduce average energy use to $600 \mathrm{kWh} /$ year. Furthermore we used a sample distribution of monthly household electricity consumption collected by the Energy Foundation to estimate how many households fall into which rate category, and on this based calculated a weighted average marginal price of electricity as $\$ 0.065 / \mathrm{kWh}$. Shipments estimates were estimated through analysis of market intelligence data purchased from Gobi International (Gobi International, 2004). 
With respect to the cost of more efficient refrigerators, available data indicates that there is no correlation in the marketplace between energy use and purchase price for refrigerators in Ghana. But this does not imply that there will be no cost for increasing the average efficiency of the refrigerators in the marketplace. Instead it means that there will need to be a market transformation process that will eliminate or rehabilitate the less efficient refrigerators leaving refrigerators that are compliant with program efficiency targets. The average unit cost of this market transformation process is as yet unknown. Since it is unknown at this time what the cost of efficiency improvements might be in the Ghanaian context, we calculate only potential program benefits, as a way of defining the resources that can justifiably be invested in a market transformation program.

\section{Model Results}

Figure 3 shows the estimated future benefits of a refrigerator market transformation program in Ghana beginning in 2010 in units of dollars/person/year. The calculation assumes that such a program is equivalent to a mandatory standard that moves the market to refrigerators that consume an average of $600 \mathrm{kWh} /$ year of electricity starting in the year 2010. The benefits from a potential program increase linearly starting in 2010 as the old stock of inefficiency refrigerators is replaced by more efficient models at the rate of approximately 60,000 units/year. 


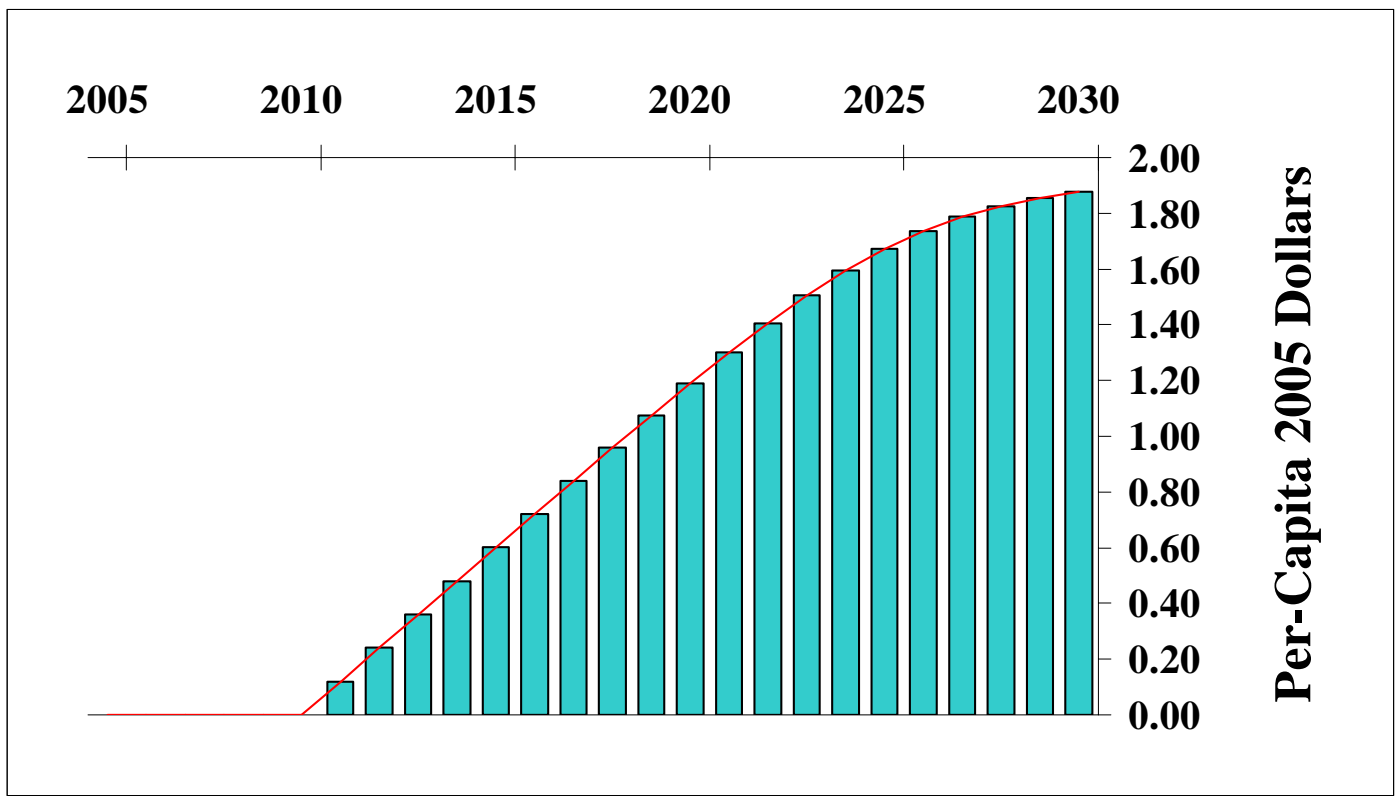

Figure 3: Estimated annual per-capita benefits of a refrigerator efficiency market transformation program in Ghana

While the forecasted benefit may seem modest by developed country standards, the daily wage for many workers in Ghana is less than $\$ 2 /$ day. Once inefficient refrigerators are replaced with more efficient models, the benefit in Ghana reaches \$1.8/capita/year. Given the average household size in Ghana of five people, the benefit of a refrigerator standard reaches a value equivalent to approximately a week of unskilled labor per year.

From the consumer perspective, the average annual savings per refrigerator is approximately $\$ 35 /$ year. This is a very substantial savings considering that a typical refrigerator price is around \$100 in Ghana. Given the PAMS default real consumer discount rate of $11.6 \%$, this provides a life-cycle cost savings of \$245/refrigerator which is nearly two and a half times the typical purchase price of a refrigerator. 


\section{Net Present Value of Economic Benefits}

Using a real national discount rate of $10 \%$ to reflect the relatively higher cost of capital in Ghana, the present value of the benefits from a refrigerator market transformation program from 2010 to 2030 is $\$ 94.8$ million which is $2 \%$ of estimated 2004 GDP (CIA, 2005). In comparison, the cumulative net benefit of refrigerator standards for the U.S. economy from 1987 to 2050 is estimated at $\$ 40$ billion (Meyers et.al., 2003) or $0.3 \%$ of 2004 US GDP (CIA, 2005) Thus, especially in terms of relative national economic impact, a refrigerator efficiency market transformation program in Ghana may be more important than similar programs in developed countries.

\section{Carbon Emissions Reductions}

Figure 4 illustrates the estimated carbon emissions reductions from a refrigerator efficiency market transformation program in Ghana. The estimated cumulative emissions reductions are 380,000 metric tons up to 2020 , and $1,370,000$ metric tons through 2030. The annual emissions reductions increase linearly from 2010 from zero to approximately 100,000 tons/year in 2025. 


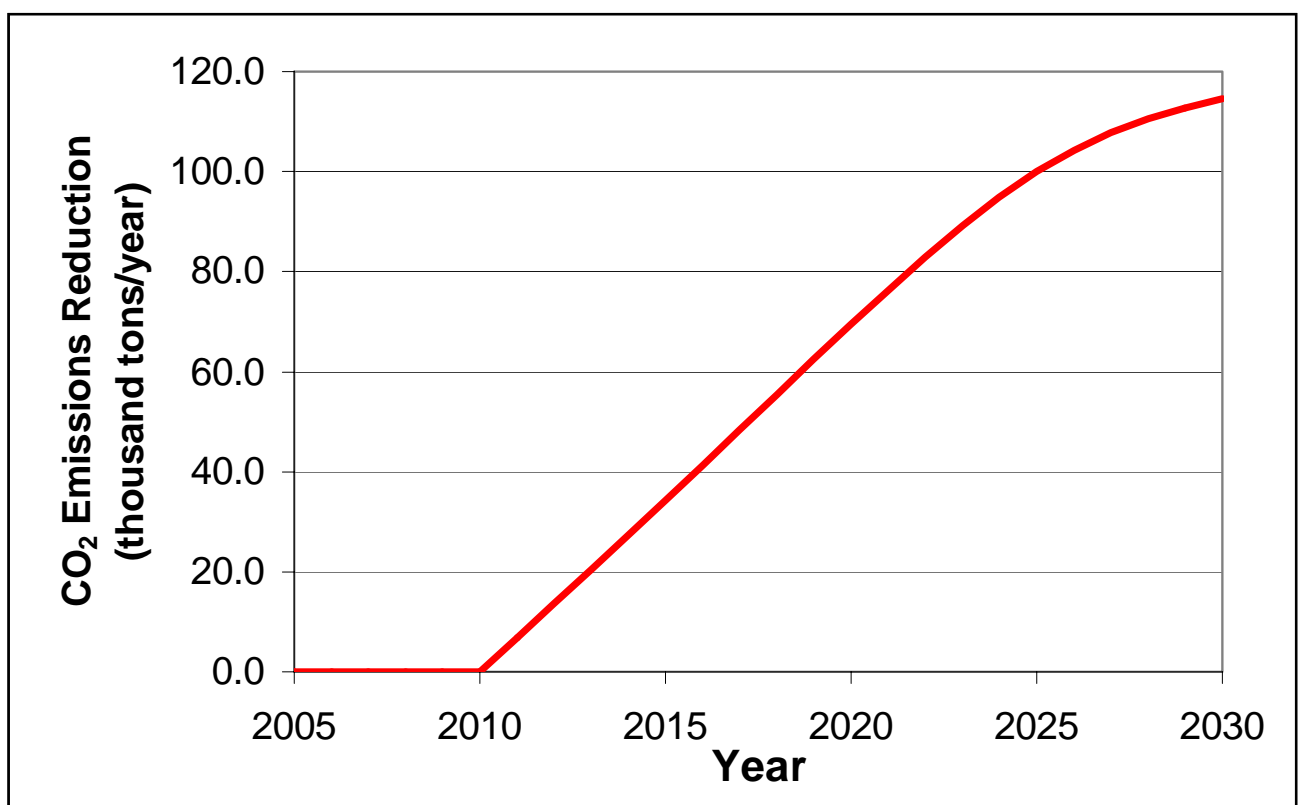

Figure 4: Estimated annual carbon emissions reductions from a refrigerator efficiency market transformation program in Ghana

In some sense, the economic cost of these emissions reductions is negative. That is, there is likely a net benefit from the implementation of the market transformation program that produces the emissions reduction. But the programmatic investments and research needed to implement the market transformation program that will bring about this emissions reduction does have a net cost, which can be justified by attaching a forecasted value to the emissions reduction and estimating the present value of annual emissions reduction. In the case of carbon emissions reduction value of $\$ 5 /$ ton and a discount rate of $10 \%$, the present value of these emissions reductions is $\$ 1.3$ million. 


\section{Program Funding Levels}

Given an analysis of the potential benefits of a refrigerator efficiency market transformation program, we can estimate program funding levels that may be economically efficient and justified given the level of potential benefits.

A key assumption of our discussion is that an efficient allocation of international aid and cooperation is one where the funding allocation is strongly correlated with concrete, measurable attainment of the goals of the aid program. In this sense, we see three key objectives of international aid that are satisfied by efficient refrigeration market transformation programs in Africa: (1) Environmental benefits of reduced carbon emissions and CFC leakage, (2) Economic benefits of decreasing the cost of modern energy services supply, and (3) the poverty reduction benefits of decreasing the electricity bill of poor households with refrigerators. Of these three goals, the measurement of carbon emissions reduction impacts has perhaps the best developed set of performance metrics and estimation protocols. Economic benefits are probably best characterized in terms of an economic rate of return or benefit-cost ratio for invested funds. Poverty reduction is perhaps the least well defined, though it is generally agreed that activities that allow for greater access to modern energy services for poor and rural sectors of society contribute to poverty reduction.

As discussed above, the present value of future emissions reductions through 2030 estimated for a refrigerator efficiency market transformation program is $\$ 1.3$ million. Because this value represents a present value of future emissions reductions that begin in 2010 and that are discounted at 10\%/year, this present value of savings increases as the date of program implementation approaches. 
Thus there is an increase in present value of the emissions reduction savings by $\$ 130,000$ for any activity that advances the implementation of the market transformation program by one year. Thus in terms of investing in programmatic activities that can advance the implementation schedule for the Ghana refrigerator efficiency market transformation, an annual international budget of $\$ 130,000$ can be easily justified simply on carbon emissions reduction benefits alone.

\section{Conclusion and Summary}

In this paper we examined the possibility of implementing a refrigerator efficiency market transformation program in Ghana. This examination considers the particular socio-economic and institutional conditions in Ghana and is informed by recently collected data regarding refrigerator energy use. We conclude that for the Ghana refrigerator efficiency market transformation, it may be advisable to take an approach that deviates significantly from typical recommendations based on developed country experiences. In the Ghana context, a market transformation approach that focuses on the regulatory aspects of appliance testing, labeling and standards alone is unlikely to be successful. Instead in Ghana a combination of education and regulation is likely to deliver the necessary efficiency improvements. Much more initial work will need to be done on education, mobilization, design, and research on refrigerator market dynamics. With thousands of models in the market, no refrigerator manufacturers, and thousands of used refrigerator rehabilitators and repairers, it is not feasible to test and certify particular makes are models for efficiency performance as the sole enforcement mechanism. A general, simple approach will be more useful. Thus international test standards will be supplemented with a quick evaluation test that will simplify 
enforcement. On the other hand, the fact that the benefits from refrigerator efficiency are so large compared to the typical purchase price implies that it may be feasible to do efficiency rehabilitations refrigerator by refrigerator. The details of which market transformation strategies will and will not work in the Ghanaian market will take further research and investigation.

We find that previous estimates of baseline refrigerator energy use (for the sake of standards analysis) have been underestimated by a factor of two, and thus previous estimates of the energy savings potential are likely underestimated by a factor of 3-4. Furthermore, we find that previous concerns about the effect of refrigerator size and features on energy use are of relatively little importance compared to simply removing or fixing the high energy use refrigerators in the market. This provides the potential of dramatically simplifying both test procedures and enforcement. It is thus possible that Ghana may be able to use a simple 24-hour meter measurement rather than a scientifically controlled laboratory procedure and may be able to use the same general standard for all refrigerator types (e.g. $2 \mathrm{kWh}$ /day maximum). A highly simplified test procedure and maximum energy use requirement may allow Ghana to tackle the challenge of an incredibly diverse market of new and used refrigerators where there is no regularization in refrigerator construction and rehabilitation practices.

In relative national economic terms, refrigerator efficiency in Ghana may be nearly 10 times more important than refrigerator efficiency has been for developed economies like the U.S. In addition over the long-term, refrigerator efficiency programs in Ghana may provide some of the most cost effective greenhouse gas emissions reductions possible. Thus in terms of beginning 
implementation of Ghana's refrigerator market transformation program (and replicating it to other countries in Africa) activities should be advanced with the highest priority.

\section{Acknowledgements}

The authors are grateful for the assistance of Benoit Lebot, Olivier Sidler, and Alan Meier for helping with the acquisition of SEM 10 electrical meters used in the energy use data collection, and to Lesia Whitehurst, Leviticus Bull, and Lareisha Lewis for visiting Ghana to help launch and encourage the refrigerator energy use measurement program.

\section{Disclaimer}

This document was supported by work sponsored by the United States Government. While this document is believed to contain correct information, neither the United States Government nor any agency thereof, nor The Regents of the University of California, nor any of their employees, makes any warranty, express or implied, or assumes any legal liability or responsibility for the accuracy, completeness, or usefulness of any information, apparatus, product, or process disclosed, or represents that its use would not infringe privately owned rights. Reference herein to any specific commercial product, process, or service by its trade name, trademark, manufacturer, or otherwise, does not necessarily constitute or imply its endorsement, recommendation, or favoring by the United States Government or any agency thereof, or The Regents of the University of California. The views and opinions of authors expressed herein do not necessarily state or reflect those of the United States Government or any agency thereof or 
The Regents of the University of California and shall not be used for advertising or product endorsement purposes. 


\section{REFERENCES}

Bank of Ghana (2005) Monthly time series of monetary statistics,

URL: http://www.bog.gov.gh/

CLASP (2005) Energy Efficiency Standards and Labeling Information

Clearinghouse, Collaborative Labeling and Appliance Standards Program,

URL: http://www.clasponline.org.

Constantine S, Denver A., Hakim S, McMahon J.E., \& Rosenquist G. (1999)

Ghana Residential Energy Use and Appliance Ownership Survey: Final Report on the Potential Impact of Appliance Performance Standards in Ghana, report LBNL43069, Berkeley, CA, Lawrence Berkeley National Laboratory, March 30, 1999.

Cornut, Bernard (2005) ADEME Intl Division, France, (personal communication)

Energy Information Administration (2005a), End-Use Consumption of Electricity 2001, URL:

http://www.eia.doe.gov/emeu/recs/recs2001/enduse2001/enduse2001.html

Energy Information Administration (2005b), Electric Power Monthly, Average

Retail Price of Electricity to Ultimate Customers by End-Use Sector, by State,

URL: http://www.eia.doe.gov/cneaf/electricity/epm/table5_6_a.html

Ghana Statistical Service (2005) Key Social/Economic/Demographic Indicators, URL: http://www.gss.gov.gh/key.htm. 
Gobi International (2004) World Business Information: Refrigerators,

URL: http://www.gobi.co.uk/page42.htm

International Energy Agency (2005) IEA Energy Statistics, URL: http://www.iea.org/Textbase/stats/.

Karekezi S., Kimani J., Majoro L. and Kithyoma W. (2004) African Energy Data and Terminology Handbook: Year 2003 - 2004 Edition, AFREPREN/FWD Occasional Paper No. 23., AFREPREN/FWD, Nairobi, 2004.

Meyers S, McMahon J.E., McNeil M., Liu X. (2002) Impacts of US federal energy efficiency standards for residential appliances: promulgated from 1990 through 2001, report LBNL-49504, Berkeley, CA, Lawrence Berkeley National Laboratory, 2002.

Meyers S, McMahon JE, McNeil M, Liu X. (2003) Impacts of US federal energy efficiency standards for residential appliances, Energy 28 (2003) 755-767.

Shrestha R.M., Jalal A.I., Latif M., Biswas W.K. (1998) Mitigation of power sector environmental emissions through energy efficiency improvements: the case of Pakistan, Journal of Environmental Management 54, 249-258, Article No. ev980231.

United Nations Development Program (2005) Human Development Reports, 
URL: http://hdr.undp.org/.

U.S. Central Intelligence Agency (2005) The World Factbook - Rank Order GDP (purchasing power parity),

URL: http://www.cia.gov/cia/publications/factbook/rankorder/2001rank.html

Weil S, McMahon J.E. (2005) Energy Efficiency Labels and Standards: A

Guidebood for Appliances, Equipment, and Lighting, 2nd Edition, Collaborative Labeling and Appliance Standards Program (CLASP), Washington, D.C., USA, February 2005. URL: http://www.clasponline.org/files/Guidebook_2ndEdition.pdf 